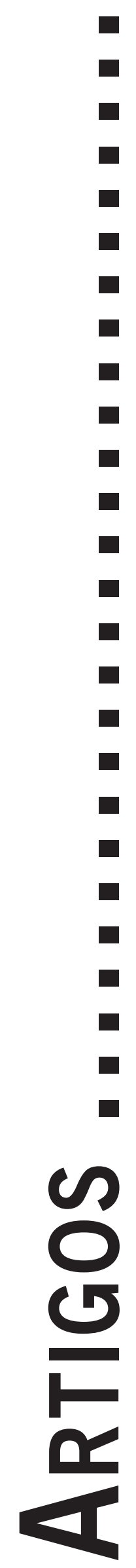




\title{
FORMAS DE EXISTIR: A BUSCA DE SENTIDO PARA A VIDA
}

\author{
Forms of Being: The Search for Life's Meaning \\ Formas de Existencia: La Búsqueda de Sentido en la Vida
}

Cláudia Carneiro

StelLA ABRitTA

\begin{abstract}
Resumo: As autoras fazem uma reflexão sobre a busca de sentido para a vida a partir das criações e formas de existir com as quais o homem representa sua necessidade de garantir a sobrevivência e de transcender-se. Se, no início, o homem parecia resolver a questão da sobrevivência com aparatos mais simples, como comida, abrigo e prole, hoje, apesar de todos os recursos à sua disposição, enfrenta uma crise de valores na busca de propósitos que possa dar à vida e ao existir. A trajetória humana na construção desse sentido passa pela invenção da beleza, da arte, do sagrado, do sonho desperto. Recorrendo a fatos da antropologia e a criações na literatura e arte, as autoras abordam sobre a contemporaneidade, o vazio existencial e as formas de expressão humana para re-significar a existência.
\end{abstract}

Palavras-chave: Sentido da Vida; Humanismo; Gestalt-terapia; Psicoterapia; Vazio Existencial.

\begin{abstract}
The authors reflect about the search for life's meaning based upon the creations and forms of being, with which man represents his need to guarantee survival and transcendence. If, in the beginning, man seemed to deal with the question of survival with simpler instruments, such as food, shelter and brood, today, despite having all the resources at his disposal, he comes up against a crisis of values in his pursuit for meanings which with he could provide to life and existence. The human journey in the construction of this meaning goes through the invention of beauty, art, that which is sacred and daydreaming.Calling upon anthropological facts and creations in literature and art, the authors discuss about contemporarity, existential void and the human expression forms to resignify existence.

Keywords: Life Meaning; Humanism; Gestalt-therapy; Psychotherapy; Existential Void.

Resumen: Las autoras reflexionan sobre la búsqueda de sentido en la vida y como el hombre a partir de sus creaciones y formas de existencia garantiza su supervivencia y su trascendencia. Si en el inicio, el hombre parecía resolver la cuestión de la supervivencia con aparatos más simples, como comida, abrigo y prole, hoy, a pesar de todos los recursos a su disposición, enfrenta una crisis de valores en la búsqueda de intentos que pueda darle a la vida y a la existencia. La trayectoria humana en la construcción de ese sentido pasa por el invento de la belleza, del arte, de lo sagrado, del sueño despierto. Recorriendo los acontecimientos de la antropología y las creaciones en la literatura y el arte, las autoras abordan sobre la contemporaneidad, el vacío existencial y las formas de expresión humana para resignificar la existencia.

Palabras-clave: Sentido de la Vida; Humanismo; Terapia-gestalt; Psicoterapia; Vacío Existencial.
\end{abstract}

Ao longo da existência, o homem buscou construir sentido para sua razão de ser e de estar no mundo. Desde a luta pela sobrevivência, a ocupação do território e a formação das sociedades primitivas, ele aos poucos foi tomando consciência de sua singularidade e condição diferenciada das outras espécies e, cada vez mais, desenvolvendo meios para afirmar sua presença no mundo e dar sentido a ela.

A filosofia, a arte, a literatura, as tradições e os rituais expressaram, na história da humanidade, o sentido da vida e a participação do homem no mundo. Com estas manifestações, buscou externar suas indagações e necessidades mais básicas a respeito da existência, na tentativa de compreendê-las. Construiu valores e sustentou tradições, geração após geração, para transmitilos. Tais valores podem ser entendidos como acepções universais.
Todas essas criações e formas de existir representam, em última instância, a necessidade do homem de garantir a sobrevivência. Em seu livro Um Sentido para a Vida, o psiquiatra Viktor Frankl (1989) e fundador da logoterapia, que ele definiu como a terapia através do sentido, afirma que a sobrevivência do ser depende da capacidade de orientar a própria vida em direção a um "para que coisa" ou um "para quem", ou seja, a capacidade do ser de transcender-se.

Se, no seu início, o homem parecia resolver a questão da sobrevivência com aparatos mais simples - comida, abrigo, prole - hoje, apesar de todos os recursos à sua disposição, sua condição de permanência na Terra parece uma tarefa cada vez mais penosa. A crise de valores por que passamos na atualidade nos remete a uma questão primordial: Que sentido tem a vida? Que propósito podemos dar à vida e ao existir, depois do genocídio pa- 
trocinado pelo nazismo, depois da bomba atômica e da ameaça de um botão vermelho, com o qual apenas um clique seria o suficiente para o extermínio da humanidade, e da sorte de milhões de crianças que no século XXI ainda morrem de fome?

A tecnologia trouxe o paradoxo da sobrevida e da autodestruição do ser humano. Tudo está pronto, a ponto de ser consumido e não mais exige do homem a construção de um sentido para tal: a poesia deu lugar ao mundo virtual, a sensualidade é objeto de marketing, a privacidade sucumbiu à sedução das comunidades on-line. $\mathrm{O}$ corpo está exposto e a intimidade devassada. Os jovens buscam nas drogas alguma compensação para a falta de uma razão de ser e de existir.

Mas o homem mantém sua perplexidade e inquietação na busca de um sentido para a vida. Cabe-nos indagar se isso é alcançável ou não, e, ainda, como fazê-lo.

\section{A Trajetória Humana na Busca de Sentido para a Vida}

Uma rápida passagem por alguns fatos antropológicos pode dar-nos maior dimensão de como nossos ancestrais já buscavam na natureza e na própria psique um contexto que justificasse suas vidas. Pouco a pouco, o homem inventou a beleza, a arte, o sagrado, o sonho desperto. Como afirmou Jean Clottes no livro A mais bela história do Homem (Langaney, Clottes, Guilaine \& Simonnet, 2002), a arte existe desde que o homem transformou a realidade por meio da imagem mental que dela fez. Clottes ressaltou que quanto mais nos interrogamos sobre o nascimento do senso artístico, mais descobrimos que este é bem antigo. Segundo o francês, especialista em arte rupestre, os vestígios de ações "não utilitárias" remontam a um passado de até 300.000 anos.

O mesmo desejo ancestral de significar a vida levou o homem das grutas a cultuar a morte e dar testemunho de seu próprio mistério. Movido por esse desejo, gravava na pedra corpos de animais, criava esculturas e outros objetos de arte e começava a desenvolver uma linguagem única que o diferenciou para sempre do macaco. Sabe-se que há 100.000 anos pessoas enterravam seus mortos na Palestina com ritos funerários, em cujos túmulos foram encontrados pólens de flores e oferendas de chifres de veado (Langaney et al., 2002). Um achado arqueológico da tentativa de re-significar a experiência emocional vivida com a perda e a separação!

Os rituais eram usados por nossos antepassados para dar sentido às coisas e situações que não podiam ser realizadas e experimentadas concretamente. O homem sempre se ocupou de rituais e tradições para simbolizar seus valores, crenças, pensamentos e desejos - valores que foram em parte perdidos e esvaziados ao longo do tempo.

Wolfgang Lind (2004), professor de psicologia da Universidade de Lisboa, propõe que os rituais conce- dem-nos um tempo e um espaço protegido para refletir sobre os eventos da transformação, e envolve-nos com a sua curiosa mistura de componentes familiares e desconhecidos. Escreve o autor: "Os rituais ligam-nos ao passado, definem a nossa vida presente e apontam caminhos para o futuro, quando passamos de cerimônia em cerimônia, quando evocamos tradições de nossos antepassados e quando herdamos objetos e símbolos de nossos ascendentes" (p. 3).

A imagem transmitida por Lind é a de que os rituais constituem "as lentes pelas quais podemos ver e vivenciar" as nossas ligações emocionais com o mundo. Ele atribui aos rituais a característica de nos dar o "espaço necessário para explorar o significado das nossas vidas e para reconstruir as nossas relações intra e extra-familiares" (2004, p. 2).

De fato, o que Frankl (1989) em seu livro Um sentido para a vida nos chama a atenção é que o desejo de sentido é um "valor de sobrevivência". Ele conta que aprendeu esta lição nos três anos passados no campo de concentração de Auschwitz e Dachau:

As coisas mais idôneas para a sobrevivência nos campos de concentração eram as orientadas para o futuro - para uma tarefa ou para uma pessoa que, durante a espera, eram projetadas no futuro e para um sentido da vida que no futuro iriam realizar (p. 28).

Nesse relato de sua experiência pessoal, o autor ressalta ser bem verdade que a única coisa que poderia sustentar um homem numa situação de adversidade extrema como aquela vivida em Auschwitz e Dachau era " $a$ consciência de que a vida tem um sentido a ser realizado, mesmo que no futuro" (1989, p. 28).

O fato antropológico primordial, para Frankl, é que o homem deva estar sempre endereçado a algo diferente dele próprio, para um sentido a realizar, para outro ser humano a encontrar, para uma causa à qual se entregar, para uma pessoa a quem amar (1989, p. 28).

\section{O Sentido da Vida Expresso na Literatura e na Arte}

A obra literária é um sistema aberto, portanto inacabado. Envolve o leitor em seu conteúdo, propício para ser interpretado e reinventado. Como não lidam com um sistema fechado, os poetas criam representações e oferecem sua obra para que seja interpretada por cada leitor que entre em contato com ela, à sua própria maneira. O poeta é capaz de tocar o interior de quem o lê e, por sua vez, o leitor se sente tocado pelo interior do poeta.

A necessidade de construir sentidos - já que não os tem prontos - por meio do exercício do imaginário é muito bem retratada na obra do poeta Castro Alves. Ele dispunha de uma capacidade de representar estados emocionais e envolver o leitor em cada frase de suas poesias. 
Enquanto descrevia as cenas de seu imaginário, sua sensibilidade permitia prever as sensações que sua poesia produziria no leitor.

Com sutileza, Castro Alves conseguia transmitir ao leitor a sensualidade imaginada por ele nas cenas que criava nos seus versos, tal como o fez nas palavras a moça que se despia tirando os sapatos. A mulher sensual que descreveu é uma figura que não está exposta, banalizada, nem disponível para ele.

A vida necessitava ser descoberta; os cenários precisavam ser construídos; o amor precisava ser desejado e conquistado. Nos costumes da sociedade do século XIX, o simples fato de uma mulher tirar o sapato era uma imagem impregnada de sensualidade, que o poeta muito bem conseguia descrever e representar em sua poesia.

A arte é veículo que o homem utiliza também para expurgar suas emoções. Tem função catártica. Um clássico exemplo de seu uso como purgação das emoções encontrase na secular obra literária de Leon Tolstoi, Guerra e Paz. Tolstoi revela, no decorrer de sua obra, como primeiramente o artista precisa ter um sentimento, vivenciá-lo na sua profundidade, para posteriormente expressá-lo na arte.

Tolstoi serviu no Exército durante as guerras do Cáucaso e a Guerra da Criméia. Participou de operações militares, viu e sentiu o soldado russo e pôde ser o grande pintor de uma das cenas capitais da história de sua pátria. Produziu então uma obra-prima destinada a expressar seus sentimentos e, como poucos conseguiram fazê-lo, dar vida aos personagens assim como vemos pessoas na vida real.

Em Guerra e Paz, escrito entre 1864 e 1869, Tolstoi conseguiu passar a sensação da Rússia ameaçada de 1812, mesmo tendo nascido em 1828, e, atestam os críticos, o fez melhor do que qualquer historiador. Afirma-se que ninguém ainda conseguiu superar as suas descrições de batalha. Dessa forma, o escritor evoca no leitor os mesmos sentimentos que vivenciou intensamente (SeymourSmith, 2002).

Uma pintura de cenas da guerra em forma de prosa; versos de um bombardeio militar, pintados em tela. $\mathrm{O}$ sentido de fortes experiências vividas perpassa desta maneira a obra de Tolstoi e chega à arte de Picasso. De personalidade artística predominante no século XX, Pablo Picasso (1881-1973) foi um dos mais criativos gênios de todos os tempos. A pintura era uma de suas obsessões. Sua personalidade inquieta traduzia a necessidade de fazer coisas. Gostava de experiências intensas e conheceu grandes extremos: amor e ódio, pobreza e riqueza, bajulação e desprezo, sentimentos expressos em suas obras (Cumming, 1998).

Movido pela emoção, ao saber do ataque à cidade de Guernica, bombardeada pelos nazistas para efeito de experiência militar, em 1937, Picasso pintou a tela Guernica, com o propósito de denunciar as mortes que destruíam a Espanha na Guerra Civil (1936-1939) e delatar a desumanidade do homem (Cumming, 1996).

Com intensidade semelhante, o mestre do impressio- nismo francês Vincent Van Gogh (1853-1890) expressava na arte suas lutas emocionais e seus sentimentos, por meio das rápidas e espessas pinceladas, no desespero de captar suas percepções e emoções mais imediatas.

Van Gogh era um homem sensível, inteligente e apaixonado, porém sua existência foi seguida de rejeições. Vivenciou nos últimos anos de vida um longo período de angústia e depressão, retratadas vivamente na sua arte e encerradas com o suicídio.

Voltemos à poesia para falar de sentido recorrendo a uma realidade mais familiar. Cheguemos à nossa época, à nossa gente, à brasilidade atual através dos versos de Vinícius de Moraes, o poeta que denunciou em seus poemas a paixão, dor e alegria vividas por ele frente à expectativa de todo novo amor.

Os versos de Vinícius denotam a sensibilidade de alguém que perseguiu em sua vida o objeto ideal; em cada experiência amorosa quis o encontro que não fosse imortal, posto que o amor é chama; mas eterno, enquanto possível de existir.

O poeta nos ensina que a vida só tem sentido para quem se deu. Ou seja, a experiência perpassa o ser e, por aí, dá qualidade à existência. Conhecer é experimentar. Vinícius de Moraes traduziu os sentimentos cotidianos e os mais profundos com a propriedade de quem falava de sua própria experiência, que revela no poema Como dizia o poeta, escrito a quatro mãos com Toquinho em 1970:
Quem já passou por essa vida e não viveu
Pode ser mais, mas sabe menos do que eu
Porque a vida só se dá pra quem se deu
Pra quem amou, pra quem chorou, pra quem sofreu, ai.
Quem nunca curtiu uma paixão
Nunca vai ter nada, não.
(Moraes, 2005, p. 103)

\section{A Contemporaneidade e o Vazio Existencial}

O poeta, em sua eterna busca pelo objeto ideal, sugere o encontro com o vazio. Falamos de um vazio que pode ser criativo, expansivo e transformador. Mas, o que vivemos na atualidade é a morte das ideologias, o domínio da tecnologia em detrimento do contato com o outro, a perda das tradições, o empobrecimento do ser e a supervalorização do ter, a neurose de massa.

Frankl (1989) define como uma neurose de massa o vazio existencial, que vem crescendo e se difundindo nos Estados capitalistas e tecnologicamente desenvolvidos, e não se limita a estes. É cada vez mais presente também em sociedades de ideal socialista e países do terceiro mundo.

O homem do século XXI busca na virtualidade um substituto para a relação afetiva consistente. Engana seu estado de solidão e sentimento de vazio existencial com os milagres oferecidos pela tecnologia, o celular, a internet, a relação virtual. 
Num mundo tão acessível, o homem contemporâneo busca o prazer imediato, o qual é descartável. Com a exacerbação do prazer pelo prazer, a pessoa se esvazia e tira de si própria a oportunidade de experimentar, na sua essência, afeto por outras pessoas. Seu mundo interno se transforma num grande buraco, cheio de sentimento de irrealidade, de estranheza, de vazio existencial e de uma conseqüente solidão desamparada (Vieira, 2003).

Em artigo que leva esse nome, Vieira define a solidão desamparada como "aquilo que me faz sentir não sozinho, mas abandonado, medroso, fóbico, vazio e prestes a ruir na dimensão da sobrevivência humana, psíquica” (p. 2). Vieira propõe que por detrás da síndrome do pânico, tão conhecida dos atuais tempos de vazio existencial, paira uma depressão por solidão desamparada.

$\mathrm{O}$ autor e psicanalista cita um depoimento, não raro de ocorrer no setting terapêutico:

Não agüento mais, nada tem mais sentido, mesmo que do ponto de vista material eu não me queixe da vida. Tenho uma profissão, tenho amigos, tenho tudo que quero! Mas sinto-me vazio, com medo, inseguro, sem tesão, sem projetos, sem ninguém. Acho que nesta vida nunca gostei de ninguém... (Vieira, 2003, p. 3).

Esse desabafo, que tão bem se encaixa nas angústias vividas nos tempos atuais, exemplifica a melancolia de alguém sem vínculos verdadeiros, sem consistência íntima, mergulhado num vazio existencial e na falta de uma razão de ser. Esta pode ser entendida também como a falta de um endereçamento para o outro, para uma causa, uma pessoa, um sentido a realizar, como reiterou Frankl (1989).

O homem contemporâneo vive sem raízes. O desmoronamento das tradições, observado, sobretudo, nas gerações mais jovens, é o fenômeno que pode, para Frankl, explicar o tão atual vazio existencial.

O homem não pode mais ser considerado apenas como uma criatura cujo interesse fundamental é o de satisfazer as pulsões, de gratificar os instintos, ou então, dentro de certos limites, de reconciliar entre si o id, e ego e o superego, nem a presença humana pode ser entendida simplesmente como o resultado de condicionamentos ou de reflexos condicionados. Neste âmbito, ao contrário, o homem se revela como um ser em busca de um sentido. O esvaziamento dessa busca explica muitos males de nosso tempo (p. 11).

\section{Quando o Caminho é Ressignificar a própria Existência}

Estamos mais habituados a descobrir sentido na criação, como na arte e na poesia, ou na construção de vínculos afetivos. Mas não estamos acostumados a descobrir sentido no vazio. Assim como os sentidos são únicos, eles também são mutáveis. O que pode nos levar a descobrir algum propósito também em situações desfa- voráveis, quando enfrentamos um destino que não pode ser mudado.

Ao falar de suas experiências pessoais no front de guerra contra os nazistas, o psicanalista inglês Wilfred R. Bion nos presenteia com a rica lição de como tirar proveito de um mau negócio ${ }^{1}$, o que seria dizer o mesmo que como fazer do limão uma limonada. Isto é ressignificar a experiência vivida. Talvez possamos assim descrever, em uma forma mais simplista, a proposta da teorista humanista.

Frankl remete-nos ao que chama de exemplo mais convincente do sentido verdadeiro do sofrimento - que só tem sentido quando quem sofre muda para melhor: 0 conto A morte de Ivan Ilitch, escrito por Leon Tolstoi entre 1884 e 1886.

Ivan Ilitch pode ser comparado ao homem comum do nosso tempo, imediatista e pragmático, produto de uma sociedade informatizada, massacrada nos grandes centros urbanos. Sociedade que assiste aos problemas fundamentais da existência com indiferença em relação à dor, à verdade e à precariedade. Quando Ivan Ilitch se depara com a doença, a morte e o egoísmo dos outros, irrompem nele a angústia e o desespero. Ele paga o alto preço da falta de sentido, o poço sem fundo do sofrimento total.

Por três dias, o personagem de Tolstoi gritou de dor no leito de morte, sem que nada o aliviasse. Quando seu filho entrou no quarto e viu o pai gritando, começou a chorar. "Nesse instante precisamente, Ivan Ilitch sentiu-se cair, viu a luz no fundo do negro saco e foi-lhe revelado que, embora sua visão não fosse o que poderia ter sido, ainda podia ser retificada" (Tolstoi, 1997, p. 90). Olhando para o sofrimento da esposa e do filho, Ivan Ilitch conseguiu ver algo através das lágrimas. Despertou-lhe um sentimento profundo de pena pelo sofrimento deles. Entendeu que sua condição era um tormento para a família e lamentou o fato de que sua morte representaria sofrimento para outros, mas também lhes traria descanso e libertação.

De repente, sentiu muito vivamente que os motivos de seu tormento e opressão iam-se dissipando. Procurou o temor cotidiano da morte e não o encontrou. Não havia mais temor, porque não havia morte. "A morte já não existe!", exclamou, antes de aspirar profundamente, interromper a respiração e morrer (p. 91).

Quando não temos mais condição de mudar uma situação, como no caso extremo de Ivan Ilitch, diante da morte, ainda podemos ser estimulados a mudar a nós mesmos. O confronto com a morte e a constatação de que havia desperdiçado sua vida mudaram Ivan Ilitch, levando-o a ressignificar sua existência, a crescer para além de si e a renascer maior do que antes, mesmo estando à beira da morte.

Nesse ponto de vista, o homem estará, para sempre em sua existência, na busca de um sentido para a vida.

Jorge Ponciano Ribeiro, autor de vários livros de Gestalt-terapia, traz-nos um belo exemplo dessa eterna

\footnotetext{
1 Do original inglês Making the best of a bad job, artigo publicado por Bion em 1979.
} 
busca. Depois de algum tempo estando com um cliente, Ponciano ouviu dele a seguinte exclamação: "Doutor, estou aqui porque minha vida não tem sentido!" Com um olhar profundo, dirigido ao seu cliente, o terapeuta respondeu-lhe: "Não é que sua vida não tenha sentido. É que o sentido da sua vida é não ter sentido." (Palestra proferida no Curso de Psicologia do Centro de Ensino Superior de Brasília - Iesb, 20 de novembro de 2006).

Para nós, o sentido da vida está no viver. Estando vivos, recorremos sempre a um sentido, mesmo que não nos seja clara nossa intencionalidade. $\mathrm{O}$ trecho a seguir, da obra de Paul Auster (2004), A Invenção da Solidão, nos permite uma aproximação, pela via poética, do conceito que buscamos desenvolver ao longo deste artigo.

Se a voz de uma mulher que conta histórias tem o poder de trazer crianças ao mundo, é também verdade que uma criança tem o poder de dar vida a histórias. Dizem que um homem ficaria louco se não pudesse sonhar à noite. Do mesmo modo, se não é permitido a uma criança entrar no imaginário, ela nunca se verá frente a frente com o real. A necessidade de histórias que a criança sente é tão fundamental quanto sua necessidade de comida, e se manifesta da mesma forma que a fome. Conte-me uma história, diz a criança. Conte-me uma história. Conte-me uma história, papai, por favor. O pai então se senta e conta uma história para o filho. Ou então se deita no escuro ao lado dele, e começa a falar, como se não houvesse mais nada no mundo senão sua voz, contando uma história no escuro para seu filho. Muitas vezes é um conto de fadas, ou uma história de aventuras. Porém, muitas vezes não passa de um simples salto para o imaginário (p. 172).

\section{Referências Bibliográficas}

Auster, P. (2004). A invenção da solidão. São Paulo: Cia das Letras.

Cumming, R. (1996). Para entender a arte. São Paulo: Editora Ática S.A.

Cumming, R. (1998). Para entender os grandes pintores. São Paulo: Editora Ática S.A.

Langaney, A., Clottes, J., Guilaine, J. \& Simonnet, S. (2002). A mais bela história do homem: de como a Terra se tornou humana. Rio de Janeiro: Difel.

Lind, W. (2004). A importância dos rituais familiares na construção da família. Revista Cidade Solidária [online], 11, 6-23. Acesso em 22 de outubro, de 2006, em http://www.scml.pt/ direscrita/media/revista/rev_11/rituais_familiares.pdf.

Frankl, E.V. (1989). Um sentido para a vida: psicoterapia e humanismo. Aparecida, SP: Editora Santuário.

Moraes, V. (2005). Texto de José Castello. Em Livro de Letras (p. 103). São Paulo: Companhia das Letras.

Seymour-Smith, M. (2002). Os 100 livros que mais influenciaram a humanidade: a história do pensamento dos tempos antigos à atualidade. Rio de Janeiro: Difel.

Tolstoi, L. (1997). A morte de Ivan Ilitch. (Trad. Carlos Lacerda). Rio de Janeiro: Lacerda Editora. (Original publicado em 1886).

Vieira, C. (2003). Solidão desamparada. Boletim Informativo da Sociedade de Psicanálise de Brasília, 9 (5), 2-3.

Cláudia Aparecida Carneiro - Acadêmica de Psicologia no Instituto de Educação Superior de Brasília (IESB) e membro do Instituto de Psicanálise Virgínia L. Bicudo, da Sociedade de Psicanálise de Brasília (SPB). Endereço para correspondência: SHIS QI 09, Bloco E II, sala 309 (Lago Sul). CEP: 71625-009 - Brasília/DF.

Email: claudiacarneiro@terra.com.br

Stela Dalva Abritta - Acadêmica de Psicologia no Instituto de Educação Superior de Brasília (IESB). Endereço para correspondência: SQN 305, Bloco H, apto 504 - Asa Norte. CEP: 70737-080 - Brasília/DF.

Email: stelaabritta@uol.com.br

Recebido em 09.09.08 Primeira Decisão Editorial em 12.12.08 Aceito em 05.03.09 